\title{
"Study of Blood Glucose Level on Admission As Potential Indicator for Mortality in Non-Diabetic Patients with Acute Myocardial Infarction"
}

\author{
Dr Maitrey Patel ${ }^{1}$, Dr Basavaraj R Patil Raikood ${ }^{2}$, Dr Suresh Chincholi ${ }^{3}$ \\ ${ }^{I} P G$ Department Of General Medicine MRMC, Kalaburgi \\ ${ }^{2}$ Associate Professor, Department Of General Medicine, MRMC, Kalaburgi, \\ ${ }^{3}$ Professor \& HOD, Department Of General Medicine, MRMC, Kalaburgi, \\ Department Of General Medicine, Mahadevappa Rampure Medical College, Kalaburgi, Karnataka, India
}

\begin{abstract}
Background: In recent years, much attention has been given to the evidence that the concomitant occurrence of hyperglycemia in patients with an acute myocardial infarction (MI) enhances the risk of mortality and morbidity, whether the patient has diabetes or not.

Objectives: To analyze impact of admission glycaemia on hospital stay mortality in non-diabetic patients presenting with acute myocardial infarction.

Methods: The study was conducted on 50 cases of AMI admitted at Mahadevappa Rampure Medical College, Kalaburagi, Karnataka, India during the year 2015-2016. The cases were divided into 4 groups (group I to IV) based on admission RBS. There were 14 patients in Group I (admission RBS < 120mg \%), 8 patients in Group II (admission RBS 120-140mg \%), 12 patients in Group III (admission RBS 141-167mg \%), 16 patients in Group IV (admission RBS > 167mg \%). All cases were subjected to investigation, and in-hospital complications were noted. They were also followed up for 30 days. In hospital complications and 30-day mortality was analyzed using appropriate statistical methods across the groups (I- IV).

Results: Of the 50 cases, all had ST segment elevation myocardial infarction. Age and sex were comparable between the groups but patients aged $>60$ years were more common in group IV. With progressive rise in admission RBS (Groups I to IV), there was a progressive drop in mean systolic BP $(p=0.000302 *)$, mean diastolic BP $\left(p=0.0493^{*}\right)$ and LVEF $(p=0.0002 *)$, greater occurrence of arrhythmias $\left(p=0.011^{*}\right)$ and subsequent development of cardiogenic shock $\left(0.008^{*}\right)$. Patients with high admission RBS were also found to have higher admission Killip class $\left(0.01511^{*}\right)$ and increased incidence of subsequent deterioration of Killip class by $\geq 2$ classes $\left(0.029106^{*}\right)$ during the hospital stay. The 30 day-mortality occurrence increased as we progressed from group I to IV $\left(p=0.12845^{*}\right)$.

Conclusion: In our study, overall in-hospital complications were more common in subjects with high admission RBS. There was a positive linear correlation between admission RBS and 30-day mortality. Our study emphasizes that proper management strategy of glycemic state in patients with acute myocardial infarction may reduce the morbidity and mortality associated with acute hyperglycemia.
\end{abstract}

Keywords: Stress Hyperglycemia, Acute Myocardial Infarction, Diabetes Mellitus, Mortality.

\section{Introduction}

Hyperglycemia as a response to stress was firstly described by a French physiologist Claude Bernard in $1855^{1}$ Acute hyperglycemia with myocardial infarction is associated with an increased risk of in-hospital mortality in patients with and without diabetes; the risk of congestive heart failure or cardiogenic shock is also increased in patients without diabetes ${ }^{2,3}$ Elevated glucose also could be a marker of existing insulin resistance and/or beta-cell failure that may contribute to the poor prognosis through other mechanisms. Increased level of glucose could simply be a marker of pre-existing, but not yet detected type 2 diabetes or impaired glucose tolerance (IGT). ${ }^{2}$ Elevated blood glucose levels adversely affect several mechanisms, including induction of oxidative stress, endothelial dysfunction, and impaired fibrinolysis; and hypercoagulability. Thus the detrimental effect of stress hyperglycemia in acute MI might also stem from its ability to increase inflammation. Determination of blood sugar is a simple procedure, requires no expertise, is inexpensive and importantly, it is a correctable factor, having a bearing on morbidity and mortality. So this study aim is to analyse blood glucose level on admission as potential indicator for mortality in non-diabetic patients with acute myocardial infarction. 


\section{Material And Method}

From June 2015 to May 2016, 50 cases were included in our study and divided among four groups according to admission blood sugar level. Group I ( $\leq 120 \mathrm{mg} \%)$, Group II (120-140 mg \%), Group III (141-167 $\mathrm{mg} \%$ ) and Group IV (>167 mg \%).

Study included all Patients with symptoms suggestive of acute myocardial infarction lasting for 30 minutes, proven by cardiac enzymes, ECG showing at least two contiguous leads with pathological Q waves and persistent ST elevation $(>0.1 \mathrm{mV})$. Chest pain onset in the last maximum 12 hours in patients who were not diagnosed with diabetes mellitus, Normal $\mathrm{HbA}_{1 \mathrm{c}}(<7)$.

Known cases of diabetes, Patients who had received dextrose containing intravenous fluids before admission, Patient with Post surgical, post trauma (up to 1 month), burns, sepsis, Patients receiving drugs elevating blood sugar levels (e.corticosteroids), Time from the beginning of symptoms to admission to the ICCU more than 48 hours, Patients who had a treatment history of Oral Hypoglycemic agents/Insulin were excluded from study.

Following investigation was done on patients. Random blood sugar, Electrocardiography Cardiac enzymes (Troponin I and CK MB) at admission.Glycosylated hemoglobin (HbA1c), Fasting Lipid Profile , Echocardiography during hospital course.Clinicaly patients BP , HR , Cardiovascular System , Killip classification, cardiogenic shock status were noted.

Patient was followed till Death or up to 30 Days. And comparison of admission RBS and mortality was analysed according to data. Data obtained was tabulated using version 22 of the Statistical Package for Social Sciences (SPSS, published SPSS Inc.) and subjected to appropriate statistical analysis. Chi- square test and one way ANOVA with post hoc test were used to identify differences between 4 groups. Bivariate correlation using Pearson's method was used to identify different Correlates of death as outcome. Logistic regression was used to see the significant predictors of outcome as death. Informed consent was taken from all patients. Ethical committee permission was obtained for study

\section{Results}

Number of patient according to Group were , Group I- 14(28\%), Group II - 8(25\%), Group III $12(24 \%)$, group IV - 16(32\%). Mean age of patient group I - 52.1, Group II -53, Group III - 51.1, Group IV 54.4.Age $>65$, number of patient were more in Group IV. Total Male and female patient were 26 and 24 respectively. There was no significant difference among group in sex distribution. 22 patients had HTN, 24 gave history of smoking, and 16 patients consumed alcohol. But there was no significant difference prevalence among groups.

Mean systolic BP at admission was $93.63 \mathrm{~mm} \mathrm{Hg}$ in Group IV as compared to $132.28 \mathrm{~mm} \mathrm{Hg}$ in Group I, $130.00 \mathrm{~mm} \mathrm{Hg}$ in Group II and $124.67 \mathrm{~mm} \mathrm{Hg}$ in Group III. There was a statistically significant $(\mathrm{P}=$ 0.0003 ) drop in the mean systolic BP as we move from Group I to Group IV. The mean diastolic BP at admission was $60 \mathrm{~mm} \mathrm{Hg}$ in Group IV as compared to $81.43 \mathrm{~mm} \mathrm{Hg}$ in Group I, $81.25 \mathrm{~mm} \mathrm{Hg}$ in Group II and $74.67 \mathrm{~mm} \mathrm{Hg}$ in Group III.Table - 1 shows that there is a statistically significant drop in the mean systolic BP $(\mathrm{P}=0.0003)$ and mean diastolic BP $(\mathbf{P}=\mathbf{0 . 0 4 9 3})$ as we move from Group I to Group IV. There occurred no statistically significant difference in the heart rate at admission across the groups. At admission, 22 patients were in Killip class I, 15 patients in Killip Class II and 6 patients in Killip class III with 7 patients having Killip class IV. We observed that patients in Group III and Group IV had higher admission Killip class, which was statistically significant $(\mathrm{p}=\mathbf{0 . 0 1 5 1 1} *)$. Another observation was Killip class deterioration by $\geq 2$ classes during the hospital stay occurred more commonly in group III and IV. Killip class was high in subjects with higher admission RBS values. When we statistically analyzed the number of subjects with Killip class deterioration by $\geq 2$ classes during the hospital stay, among the groups, there is significant difference $(\mathrm{p}=\mathbf{0 . 0 2 9 1 0 6 *})$

There was no statistical significant difference in HbA1c, CK-MB, territory of Infarct, Fasting Lipid profile as shown in Table- 1. Admission RBS among group were, Group I - 105.37 , Group II- 124.4 , Group III -147.83 , Group IV -215.88 . Which is statistically significant $(\mathrm{p}=0.00001)$. In addition, among the group without cardiogenic shock on admission, more patients with raised glycemia subsequently developed cardiogenic shock. Mean LVEF in Group IV was $40.19 \%$ as compared to $51.25 \%, 45.00 \%, 43.75 \%$ in group I, II and III respectively. This difference in the mean LVEF measured during the hospital stay across the groups is statistically significant $(\mathrm{p}=\mathbf{0 . 0 0 0 2}$ ). In our study, it was found that higher admission RBS values were found to have higher incidence of arrhythmias. This observation is statistically significant $(\mathbf{p}=\mathbf{0 . 0 1 1})$.

30 -day mortality in our study was $0 \%$ in patients with Group I, compared with $25.00 \%$ in patients in Group II, $33.33 \%$ in Group III and $50.00 \%$ in Group IV. This difference in the incidence of 30-day mortality, which linearly increases as admission RBS rises, is statistically significant $(p=\mathbf{0 . 1 2 8 4 5})$. 
Table 2 shows shows Admission RBS, Arrhythmias, Cardiogenic Shock, and Killip's Heart Failure Class (KD \& KA) have statistically significant positive correlation with death. Systolic BP, Diastolic BP and LV Ejection Fraction have statistically significant negative correlation with death

Table 3 shows, out of all variables which have statistically significant correlation with death as an outcome, are only four variables; Arrhythmia, Cardiogenic Shock and Killip's Class (KD, KA, Killip class 4) And Admission RBS are the best predictors of death and overall this model has $86 \%$ predictability.

\section{Discussion}

Age and sex were comparable between the groups. But in a previous study by Kadri et $\mathrm{al}^{5}$ women had higher admission RBS compared to males of similar age. There was no statistically significant difference across the groups in mean age. The number of patient $>60$ years of age was also compared between the groups, which was statistically significant $\left(\mathrm{p}=0.0109^{*}\right)$ between Group I and Group II, III \& IV. Previous studies have shown that as age advances there is higher admission glycemic status, which is in accordance with the known fact that there is impaired glucose tolerance with advancing age. There was no statistically significant difference of alcohol consumption, smoker, and prevalence of hypertension between the groups. Subjects with higher admission RBS were found to have lower systolic BP and diastolic BP at the time of admission and lower LVEF. There was a statistically significant drop $(\mathrm{p}=0.0493)$ in mean diastolic BP as we move from Group I to Group IV. Probable explanation for this is that more patients in the higher admission blood glucose groups had a lower LV ejection fraction and poorer LV function. There occurred no statistically significant difference in heart rate at admission across the groups. Previous studies ${ }^{4}$ have reported similar results with respect to mean systolic and diastolic BP, but their observation was that a higher heart rate was associated with higher admission RBS values (probably due to raised sympathetic tone). There was no statistical significant difference $(\mathrm{p}=0.8254)$ in the HbAlc levels across the groups, which implies a similar glycemic status in all the study subjects prior to acute myocardial infarction (AMI). And all our study subjects had HbA1c within normal range and were comparable. Thus, glucose values at admission were purely the result of acute stress. CK-MB levels across the groups were not comparable, as estimation of enzymes was done at varying time interval, from the onset of symptoms. Earlier studies have an observation of higher level of enzymes correlated with higher admission RBS values The subjects with high admission RBS were also found to have higher admission Killip class and increased incidence of subsequent deterioration of Killip class by $\geq 2$ classes during the hospital stay. Similar result was reported by Kadri et al. ${ }^{5}$ Kadri et al reported higher incidence of atrial and ventricular fibrillations in subjects having higher admission RBS.

In hospital complications were more common in subjects with high admission RBS. Development of cardiogenic shock and incidence of arrhythmias had a linear correlation with rise in admission RBS values.Kadri et al supported similar findings

In our study admission RBS, arrhythmias, development of cardiogenic shock during the hospital stay and Killip's class at admission were positive correlates of 30-day mortality.In this study systolic BP, diastolic BP and LVEF were negative correlates of 30-day mortality.In this study admission RBS, arrhythmia, cardiogenic shock and Killip's class were independent predictors of 30-day mortality.

In our study, there was a significant positive linear correlation between admission RBS and 30day mortality. However we observed that it is not an independent predictor of death in our study. Probable explanation as to why higher admission glycemia was not an independent predictor of mortality, though it was a positive correlate of death in our study is, smaller sample size

Concentrations of cortisol, epinephrine and norepinephrine were the main determinants of plasma glucose concentration measured in non-diabetic patients with acute myocardial infarction. Relative insulin deficiency and excess catecholamines reduce glucose uptake by the ischemic myocardium and promote lipolysis and increased circulating free fatty acids. The latter inhibit glucose oxidation (the -glucose-fatty acid cyclell) and are toxic to ischemic myocardium, resulting in increased membrane damage, arrhythmias, and reduced contractility. ${ }^{9}$ Stress hyperglycemia may be a marker of extensive myocardial damage, reflecting a surge of stress hormones such as catecholamines and cortisol that produce or augment an insulin- resistant state. $\quad$ elevated blood glucose levels per se adversely affect outcome through the cumulative effects of state. elevated blood glucose levels per se adversely affect outcome through the cumulative effects of several mechanisms, including induction of endothelial dysfunction, ${ }_{1}^{11}$ oxidative stress, hypercoagulability, and impaired fibrinolysis. A positive association between hyperglycemia at the time of the admission and subsequent mortality from AMI has been reported frequently. ${ }^{3,7,12,13}$ 


\section{Conclusion}

Higher admission RBS was found to have lower systolic and diastolic blood pressure, lower left ventricular ejection fraction, higher admission Killip class with risk of $\geq 2$ classes deterioration during hospital stay, higher incidence of arrhythmia and a positive linear correlation between admission RBS and 30-day mortality. So admission RBS is a potential indicator of hospital stay mortality in nondiabetic patients presenting with acute myocardial infarction.

Table 1 Summary of Results

\begin{tabular}{|c|c|c|c|c|c|c|}
\hline $\begin{array}{l}\text { Variable } \\
\text { Admission RBS }\end{array}$ & $\begin{array}{l}\text { Group1 } \\
(\mathrm{N}=14) \\
<120 \mathrm{mg} \%\end{array}$ & $\begin{array}{l}\begin{array}{l}\text { Group2 } \\
(\mathrm{N}=8)\end{array} \\
20-140 \mathrm{mg} \%\end{array}$ & $\begin{array}{l}\text { Group3 } \\
(\mathrm{N}=12) \\
141-167 \mathrm{mg} \%\end{array}$ & \begin{tabular}{|l}
$\begin{array}{l}\text { Group4 } \\
(\mathrm{N}=16)\end{array}$ \\
$>167 \mathrm{mg} \%$
\end{tabular} & $F / x^{2}$ & P-Value \\
\hline Age & 52.1 & 53.0 & 51.1 & 54.4 & 0.59 & 0.6248 \\
\hline Age>60yrs & 63.75 & 81.33 & 68.67 & 65.73 & 5.07 & $0.0109 *$ \\
\hline \begin{tabular}{|l|} 
Sex- Male \\
Female \\
\end{tabular} & $\begin{array}{l}12 \\
2 \\
\end{array}$ & $\begin{array}{l}5 \\
3 \\
\end{array}$ & $\begin{array}{l}9 \\
3\end{array}$ & $\begin{array}{l}10 \\
6 \\
\end{array}$ & 2.43 & 0.487 \\
\hline HTN & 8 & 4 & 2 & 8 & 4.97 & 0.174 \\
\hline Smoking & 7 & 2 & 9 & 6 & 5.93 & 0.115 \\
\hline Alcohol & 3 & 1 & 4 & 8 & 3.68 & 0.298 \\
\hline BP Systolic & 132.28 & 130.00 & 124.67 & 93.63 & 7.64 & $0.000302 *$ \\
\hline BP Diastolic & 81.43 & 81.25 & 74.67 & 60.00 & 2.82 & $0.0493 *$ \\
\hline Heart Rate & 88.14 & 83.25 & 89.67 & 82.50 & 0.41 & 0.7499 \\
\hline Admission RBS & 105.57 & 124.50 & 147.83 & 215.88 & 41.19 & $<0.00001$ \\
\hline HbA1c & 5.40 & 5.44 & 5.51 & 5.59 & 0.29 & 0.8254 \\
\hline Lipid Abnormality & 5 & 2 & 4 & 6 & 0.3968 & 0.9408 \\
\hline $\begin{array}{r}\text { Killip class admission } 1 \\
2 \\
3 \\
4 \\
\end{array}$ & $\begin{array}{l}11 \\
3 \\
0 \\
0\end{array}$ & $\begin{array}{l}4 \\
3 \\
1 \\
0 \\
\end{array}$ & $\begin{array}{l}4 \\
5 \\
2 \\
1 \\
1\end{array}$ & $\begin{array}{l}3 \\
4 \\
3 \\
6\end{array}$ & 20.49 & $0.01511 *$ \\
\hline $\begin{array}{l}\text { Killip class } \\
\text { Deterioration } \\
\text { By } \geq 2 \text { classes in } \\
\text { the hospital stay } \\
\end{array}$ & 0 & 1 & 3 & 7 & 9.01 & $0.029106^{*}$ \\
\hline Arrhythmias & 2 & 4 & 9 & 10 & 11.1 & $0.011 *$ \\
\hline $\operatorname{LV}$ EF $(\%)$ & 51.25 & 45.00 & 43.75 & 40.19 & 8.11 & $0.0002 *$ \\
\hline $\begin{array}{|lc|}\begin{array}{l}\text { Development } \\
\text { cardiogenic Shock }\end{array} & \text { of } \\
\end{array}$ & 0 & 0 & 0 & 5 & 11.80 & $0.008 *$ \\
\hline 30 day-mortality & 1 & 2 & 4 & 12 & 15.215 & $0.0016^{*}$ \\
\hline
\end{tabular}

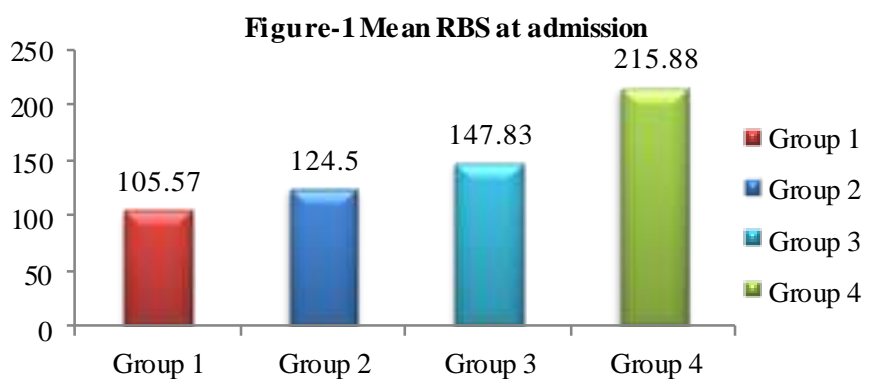


Table 2 - Correlates of 30-Day Mortality as an Outcome

\begin{tabular}{|l|l|l|}
\hline Variables & $\begin{array}{l}\text { r(Pearson } \\
\text { correlation) }\end{array}$ & P - Value \\
\hline Systolic BP & -0.3404 & $0.0156^{*}$ \\
\hline Diastolic BP & -0.3889 & $0.0052^{*}$ \\
\hline Arrhythmias (Brady \&Tachy) & 0.4454 & $0.0012^{*}$ \\
\hline Development of Cardiogenic Shock & 0.3860 & $0.0056^{*}$ \\
\hline Admission RBS & 0.4004 & $0.0040^{*}$ \\
\hline LV Ejection Fraction & -0.3860 & $0.0056^{*}$ \\
\hline KD & 0.3140 & $0.0264^{*}$ \\
\hline KA & 0.5290 & $0.0001^{*}$ \\
\hline
\end{tabular}

Table 3 - Independent Predictors of 30-Day Mortality(Logistic Regression)

\begin{tabular}{|c|c|c|c|c|c|c|c|}
\hline \multirow{2}{*}{ Variable } & \multirow{2}{*}{ B } & \multirow[b]{2}{*}{ Wald } & \multirow{2}{*}{ Df } & \multirow{2}{*}{$p$} & \multirow{2}{*}{$\operatorname{Exp}(B)$} & \multicolumn{2}{|c|}{$95.0 \%$ CI for $\operatorname{Exp}(B)$} \\
\hline & & & & & & Lower & Upper \\
\hline Arrhythmia & 2.362 & 7.930 & 1 & $0.0049 *$ & 10.615 & 2.0505 & 54.9557 \\
\hline Cardiogenic Shock & 2.639 & 5.052 & 1 & $0.0246^{*}$ & 14.000 & 1.4018 & 139.8183 \\
\hline Killip's Admission & 1.19598 & 10.6721 & 3 & $0.0011 *$ & 3.307 & 1.6135 & 6.7770 \\
\hline Killip class 1 & -1.411 & 3.714 & 1 & 0.0540 & 0.244 & 0.0581 & 1.0243 \\
\hline Killip class 2 & -1.22121 & 2.1192 & 1 & 0.1455 & 0.2949 & 0.0570 & 1.5265 \\
\hline Killip class3 & 1.09861 & 1.5319 & 1 & 0.2158 & 3.0000 & 0.5267 & 17.0877 \\
\hline Killip class 4 & 3.26767 & 8.0877 & 1 & $0.0045^{*}$ & 26.2500 & 2.7610 & 249.5695 \\
\hline Killips' deterioration & 1.537 & 4.5082 & 1 & $0.0337 *$ & 4.650 & 1.1254 & 19.2126 \\
\hline Admission RBS & 0.017138 & 6.0427 & 1 & $0.0140 *$ & 1.0173 & 1.0035 & 1.0313 \\
\hline
\end{tabular}

\section{References}

[1]. Bernard C. Lecons sur le diabeteat la glycogenase animale. Paris: Bailliere; 1877

[2]. Norhammar A, Tenerz A, Nilsson G, Hamsten A, Efendíc S, Rydén L, et al.Glucose metabolism in patients with acute myocardial infarction and no previous diagnosis of diabetes mellitus: a prospective study. Lancet 2002;359:2140-2144.

[3]. Wahab NN, Cowden EA, Pearce NJ, Gardner MJ, Merry H, Cox JL. ICONS Investigators. Is blood glucose an independent predictor of mortality in acute myocardial infarction in the thrombolytic era? J Am Coll Cardiol 2002;40:1748-1754.

[4]. Antman EM, Selwyn AP, Braunwald E, Loscalzo J. Ischemic Heart Disease. In Harrison's Principles of Internal Medicine. Editors: Fauci AS, Braunwald E, Kasper DL, Hauser SL, Longo DL, Jameson JL, Loscalzo J.18 ${ }^{\text {th }}$ edition. McGraw Hill. Vol 2. 1599-1611.

[5]. Kadri Z, Danchin N, Vaur L, Cottin Y, Gueret P, Lablanche JM, et al. Major impact of admission glycemia on 30 day and one year mortality in non-diabetic patients admitted for myocardial infarction: results from the nationwide French USIC 2000 study. Heart 2006;92:910-915.

[6]. Stranders I, Diamant M, van Gelder RE, Spruijt HJ, Twisk JW, Heine RJ, et al.Admission blood glucose level as risk indicator of death after myocardial infarction in patients with and without diabetes mellitus. Arch Intern Med 2004;164 982-988.

[7]. Suleiman M, Hammerman H, Boulos M, Kapeliovich MR, Suleiman A, Agmon Y, et al. Fasting Glucose is an Important Independent Risk Factor for 30-Day Mortality in Patients with Acute Myocardial Infarction A Prospective Study. Circulation 2005;111:754-760.

[8]. Goyal A, Mahaffey KW, Garg J, Nicolau JC, Hochman JS, Weaver WD, et al.Prognostic significance of the change in glucose level in the first $24 \mathrm{~h}$ after acute myocardial infarction: results from the CARDINAL study. Eur Heart 2006;27:1289-1297

[9]. Oswald GA, Smith CC, Betteridge DJ, Yudkin JS. Determinants and importance of stress hyperglycemia in non diabetic patients with myocardial infarction. BMJ 1986;293:917-22.

[10]. Oswald GA, Smith CC, Delamothe AP, Betteridge DJ, Yudkin JS. Raised concentrations of glucose and adrenaline and increased in vivo platelet activation after myocardial infarction. Br Heart J 1988;59:663-671.

[11]. Malmberg K, Ryden L, Efendic S, Herlitz J, Nicol P, Waldenström A, et al.Randomized trial of insulin-glucose infusion followed by subcutaneous insulin treatment in diabetic patients with acute myocardial infarction (DIGAMI study): effects on mortality at 1 year. J Am CollCardiol 1995;26:57-65.

[12]. Wong VW, Ross DL, Park K, Boyages SC, Cheung NW. Hyperglycemia: still an important predictor of adverse outcomes following AMI in the reperfusion era. Diabetes Res Clin Pract 2004;4:85-91.

[13]. Hadjadj S, Coisne D, Mauco G, Ragot S, Duengler F, Sosner P, et al. Prognostic value of admission plasma glucose and HbA1c in acute myocardial infarction. Diabet Med 2004;1:05-310 